\title{
READINESS OF THE TEACHER TO WORK IN INCLUSIVE GROUPS
}

Аннотация. В статье рассматриваются методологические аспекты, основные направления сопровождения инклюзивного образования. Дан критический анализ понятий готовности и компетентности педагога к работе в инклюзивных группах. Приводится структурный анализ готовности: составляющих, компонентов, компетенций. Обозначена проблема необходимости разработки критериев оценки готовности.

Ключевые слова: инклюзивное образование, сопровождение, готовность, компоненты готовности, компетенции.

Abstract. The article discusses the methodological aspects, the main directions of support for inclusive education. A critical analysis of the concepts of readiness and competence of a teacher to work in inclusive groups is given. The structural analysis of readiness: components, components, competencies is given. The problem of the need to develop readiness assessment criteria is outlined.

Keywords: inclusive education, support, readiness, components of readiness, competence.

Процесс гуманизации социальных отношений, характерный для современного общества в целом, несомненно, затрагивает систему образования. В условиях высшей школы это выражается во внедрении практики инклюзивного образования, предполагающего существование в едином образовательном пространстве обучающихся с различными образовательными потребностями, в том числе с инвалидностью и с ограниченными возможностями здоровья (ОВ3). Инклюзивный подход к образованию, направленный на успешную социализацию и профессиональную адаптацию данной категории студентов, требует в первую очередь адаптировать вузовскую систему подготовки к их индивидуальным образовательным потребностям, что в свою очередь предполагает изменение принципиальных подходов к содержанию, организации, образовательного процесса, его методической составляющей. Для обеспечения равных возможностей получения высшего образования студентами с инвалидностью и ОВ3 необходимо разрешить ряд проблем в области распределения полномочий и ответственности в сфере создания специальных условий для данной категории студентов: материально-технических, организационно-методических, педагогических, социально-психологических. Необходимой предпосылкой для успешного решения указанных задач являются изменения в структуре личности педагогов, начиная с изменения отношения к инклюзивному образованию и заканчивая овладением специальными знаниями, умениями и навыками педагогической деятельности.

Прежде чем выделить критерии готовности педагога высшей школы к работе в инклюзивных группах, рассмотрим существующие отечественные и зарубежные исследования по данной проблематике. Так, методологические аспекты инклюзивного образования рассматриваются в работах Е. Spandagou, D. Goodley, F. Polat, N.L. Waldron, Н.Н. Малофеева, Н.М. Назаровой, Е.И. Пургиной, М.М. Семаго и других $[4,6]$.

В структуре инклюзивного образования данные авторы выделяют следующие элементы: ценности, принципы, субъекты инклюзивного образования, а также социальные ресурсы, которые включают в себя человеческий потенциал педагогов, общественных организаций, родителей и общества в целом. Очевидно, что основная роль в реализации инклюзивного подхода принадлежит тем учреждениям и социальным группам, целью которых является удовлетворение образовательных потребностей общества. Это учреждения образования всех уровней, в том числе и высшие учебные заведения, педагоги, педагоги-психологи, учителя-дефектологи, социальные педагоги, администрации образовательных учреждений. В соответствии с нормами и ценностями инклюзивного образования происходит становление систе- 
мы поведения данных социальных групп, основанной на учете особых образовательных потребностей, индивидуальных способностей и возможностей каждого обучающегося, подготовленности педагогической общественности к эффективной профессиональной деятельности в условиях инклюзивного образования.

Признавая в качестве главной функции инклюзивного образования обеспечение равного доступа к получению качественного образования всеми его членами, большинство авторов выделяют целый ряд функций. Так, регулятивная функция заключается в построении общения и взаимодействия членов социального сообщества на основе толерантности, принятия «инаковости», сотрудничества. Раскрытие личностного потенциала каждого обучающегося на основе учета его способностей и возможностей, индивидуальных образовательных потребностей соответствует гуманистической функции, а формирование взаимной ответственности субъектов образовательного пространства, объединение усилий в достижении социально значимого результата - интегративной функции, обеспечение условий интеграции лиц с особыми образовательными потребностями в социуме - социализирующей функции. И, наконец, профессиональная функция инклюзивного образования заключается в расширении и углублении содержания профессионально-педагогической деятельности, овладении новыми профессиональными и социально-личностными компетенциями. Педагог в новых условиях расширения субъектов педагогического внимания, социальных и профессиональных контактов имеет возможность и необходимость профессионального совершенствования, расширения своей профессиональной компетентности.

B работах C. Forlin, D. Chambers, S.-K. Williams, C. Johnson, D.G. Sukhodolsky, C.B. Алехиной, Е.Н. Кутеповой, Т.В. Ветер, С.В. Федотовой излагаются направления сопровождения инклюзивного образования. Педагоги, психологи, социальные педагоги, тьюторы заинтересованы в обеспечении эффективности образовательного процесса, снижении рисков и гарантиях профессиональной безопасности. Для администрации образовательного учреждения важно повышение престижа и конкурентоспособности учреждения образования, обеспечение его эффективности. В условиях изменения общественного сознания, ценностных установок, организационных основ и содержания самой профессионально-педагогической деятельности необходимо рассматривать проблему профессиональных рисков педагога, которые выражаются в вероятности появления негативных последствий результатов педагогической деятельности в новых профессиональных условиях. Данные риски, по мнению Н.Н. Сабининой, связаны с техническим обеспечением образовательного процесса, с педагогическими технологиями, с возможными изменениями целевых установок и образовательных потребностей участников образовательного процесса [3]. Важное место в структуре рисков, по мнению исследователей, занимают коммуникативные риски и риски неопределенности ожидаемого результата образовательного процесса.

Сущность понятий «инклюзивная компетентность», «инклюзивная готовность» определена М.Ю. Айбазовой, К.Ю. Лавринец, И.Н. Хафизуллиной, Ю.В. Шумиловской, В.В. Хитрюк $[1,4]$.

Так, М.Ю. Айбазова и К.Ю. Лавринец, определяя готовность педагога к работе в условиях инклюзивного образования, отмечают, что это «сложное динамическое образование личности, позволяющее успешно осуществлять ... деятельность» $[1$, с. 82].

Готовность учителя к работе в условиях инклюзивного образования, по мнению Ю.В. Шумиловской, определяется совокупностью знаний и представлений об особенностях учащихся с ограниченными возможностями здоровья, а также владением способами и приемами работы с этими учениками в условиях инклюзии. При этом автор отмечает необходимость устойчивой мотивации педагогов к данной деятельности, что в свою очередь обусловлено сформированностью определенных личностных качеств [5].

А.Д. Гонеев, Е.Г. Самарцева, рассматривая профессиональную готовность педагога к инклюзивному образованию детей дошкольного возраста, отмечают наличие установки, которая проявляется в предрасположенности и потребности педагога в осуществлении данной деятельности, в наличии и мобилизации специальных знаний, умений и навыков [2].

Понятия готовности и компетентности педагогов в рассматриваемой литературе часто не дифференцируются: они либо отождествляются, либо рассматриваются вне 
взаимосвязи [1]. В.В. Хитрюк вводит понятие инклюзивной готовности педагога как системного интегрального качества субъекта профессиональной педагогической деятельности. По мнению автора, инклюзивная готовность предопределяет профессиональный выбор, направленность (ориентацию), поведенческие стратегии и методы профессионально-педагогической деятельности в актуальных условиях инклюивного образования [4]. В содержании инклюзивной готовности выделяются: педагогическая и психологическая составляющие; когнитивный, эмоциональный, конативный, коммуникативный, рефлексивный компоненты; академические, профессиональные и социально-личностные компетенции.

Содержание каждого компонента инклюзивной готовности, по мнению В.В. Хитрук, обусловливает образовательные результаты, которые выступают в форме компетенций: академических, профессиональных и социально-личностных. Данные компетенции в свою очередь определяют эффективность профессионально-педагогической деятельности в условиях инклюзивного образования.

В данном случае возникает вопрос, к какой группе компетенций отнести способность педагога устанавливать контакт с обучающимися на основе учета индивидуальных личностных особенностей, к профессиональным или социально-личностным. Недостаточно обосновано, на наш взгляд, выделение психологической и педагогической состав- ляющих инклюзивной готовности, так как каждый компонент структуры готовности является результатом сложного взаимодействия всех элементов структуры личности педагога. Утверждения типа «особые» дети должны и могут учиться вместе со своими сверстниками» автор относит к педагогической составляющей, а утверждение с тем же смыслом «обычный класс - оптимальное место обучения ребенка независимо от его особенностей» - к психологической составляющей.

Открытым остается вопрос о содержании критериев готовности педагога к работе в условиях инклюзии: по каким параметрам можно судить о том, насколько педагогический коллектив или отдельный педагог способен эффективно выполнять свою образовательно-воспитательную функцию в инклюзивной группе обучающихся, насколько эти параметры соотносятся между собой, как оценить изменение данных параметров с течением времени.

Таким образом, проблема готовности педагога высшей школы к работе в инклюзивных группах требует дальнейшей глубокой разработки. В частности, в уточнении нуждаются компоненты готовности, необходимо определить перечень и содержание компетенций, а также критерии оценки готовности педагога к работе со студентами с инвалидностью и ограниченными возможностями здоровья в составе студенческой группы, осуществляя при этом индивидуальный и дифференцированный подход.

\section{СПИСОК ЛИТЕРАТУРЫ}

1. Айбазова М.Ю. Подготовка будущих учителей к работе в условиях инклюзивного образования // Педагогика. 2014. № 4. С. 8286.

2. Гонеев А.Д. Проблема подготовки будущих педагогов к реализации инклюзивного образования детей с особыми образовательными потребностями // Ученые записки Орловского государственного университета. Серия: Гуманитарные и социальные науки. 2013. № 4. C. 341-345.

3. Сабинина Н.Н. Профилактика профессиональных рисков педагогов в условиях инновационной деятельности образовательного учреждения [текст]: дис. ... канд. пед. наук: 13.00.01: защищена 28.12.12 / Сабинина Нина Николаевна. - Санкт-Петербург, 2012. - 183 c.
4. Хитрюк В.В. Формирование инклюзивной готовности будущих педагогов в условиях высшего образования [текст]: дис. ... д. пед. наук: 13.00.08 защищена 21.01.16 / Хитрюк Вера Валерьевна. - Калининград: БФУ, 2015. - 390 с.

5. Шумиловская Ю.В. Подготовка будущего учителя к работе с учащимися в условиях инклюзивного образования [текст]: дис. ... канд. пед. наук: 13.00.08: защищена 22.12.11 / Шумиловская Юлия Валерьевна. Шуя, 2011. - 175 с.

6. Forlin C., Chambers D. Teacher preparation for inclusive education: Increasing knowledge but raising concerns // Asia-Pacific Journal of Teacher Education. 2011. Vol. 39, № 1 P. 17-32. 